\section{Estimating the value enhancement effects of refurbishment}

\author{
K.W. Chau \\ A.Y.T. Leung \\ C.Y. Yiu and \\ S.K. Wong
}

\section{The authors}

K.W. Chau is Chair Professor and S.K. Wong is a PhD candidate, both at the Department of Real Estate and Construction, The University of Hong Kong, Hong Kong. A.Y.T. Leung is Chair Professor and C.Y. Yiu is Assistant Professor, both at the Department of Building and Construction, City University of Hong Kong, Hong Kong.

\section{Keywords}

Refurbishment, Costing, Pricing, Models, Housing, Property management

\section{Abstract}

There have been very few empirical studies investigating the value enhancement effects of refurbishment and most rely on cross-sectional data, which cannot show the before and after effects conclusively because of the heterogeneous nature of the properties. The problem of refurbishment is more complicated in buildings or housing estates with multiple-ownerships, since refurbishment is a collective decision, which can sometimes be difficult to achieve. Uses panel data in Hong Kong to estimate the impact of refurbishment on the market value of properties in a large housing estate. The results show that the refurbishment brought about approximately a 9 per cent increase in the market value of the properties, which far exceeds the cost of refurbishment. Suggests that property owners of a housing estate will benefit if they can reach a collective decision on renovation.

\section{Electronic access}

The Emerald Research Register for this journal is available at

http://www.emeraldinsight.com/researchregister

The current issue and full text archive of this journal is available at

http://www.emeraldinsight.com/0263-2772.htm

\section{Facilities}

Volume $21 \cdot$ Number $1 / 2 \cdot 2003 \cdot$ pp. 13-19

(C) MCB UP Limited · ISSN 0263-2772

DOI 10.1108/02632770310460504

\section{Introduction}

It has often been assumed theoretically that refurbishment would enhance the market value of aged buildings because it can restore and improve the building conditions physically and economically. However, the reluctance of landlords of aged buildings to carry out refurbishment works suggests the contrary. There are several reasons for this. First, if the ownership of a building is fragmented, the negotiating cost between owners may be so high that it prohibits a collective decision from being made. Second, since owners are generally not familiar with the refurbishment process, a problem of adverse selection may arise. The lack of cost and quality information on contractors and their works may deter the owners from refurbishing their buildings. The third reason is that they may not be able to realize whether the benefits of refurbishment will outweigh the costs. The net benefits, if any, should be reflected in the market price. Focusing on the third issue, this paper attempts to construct a methodology to assess the value enhancement effects of refurbishment so as to help owners formulate their refurbishment decisions.

It is seldom empirically tested whether there are value enhancement effects of refurbishment, let alone the net value enhancement (value increases minus the cost of refurbishment). The difficulty in testing the hypothesis rests on the absence of like-withlike comparison. On one hand, since refurbishment is usually undertaken for the whole building/estate, a cross-sectional comparison of the values of flats within the same building/estate is not useful. The crosssectional comparison can be extended to other non-refurbished buildings, but this would inevitably introduce other sets of heterogeneous property attributes. For example, it is hard to distinguish the effects of refurbishment from those of other characteristics, such as locational difference. On the other hand, inter-temporal

We gratefully acknowledge the financial suppor provided by the research grant of the Research Grant Council of Hong Kong (RGC Reference Number: HKU7002/98E), The University of Hong Kong Outstanding Young Researcher Award and a grant from City University of Hong Kong (project number: 9010006).

Submitted September 2002

Revised October 2002 
comparison of the value of a flat before and after refurbishment does not help draw any conclusion because it is influenced by the overall property market. This paper aims to circumvent the above difficulties and exploits the panel data hedonic approach to test the value enhancement effects of refurbishment in Hong Kong. Several controls and crosschecks, such as the repeat-sales hedonic model, are provided to verify the results. The net value enhancement would also be presented for reference.

The paper is arranged into five sections. The ensuing section will conduct a literature review on both the theory and empirical test of the value enhancement of refurbishment. Then the methodology and data of our test will be discussed in Section 3. Section 4 will present the results of the test and controls. Conclusions will be provided in Section 5 .

\section{Literature review}

It is often assumed theoretically that refurbishment would enhance the market value of a property, but there are few empirical studies on it. Theoretical models can be traced back to Sweeney (1974), Dildine and Massey (1974), and Ohls (1975). They developed models on the opposing impacts to the rate of depreciation of maintenance, on the premise that refurbishment produced net value enhancement. Arnott et al. (1983) extended the model to include rehabilitation. Elliot et al. (1985) further extended Dildine and Massey's model by assuming that maintenance effectiveness depends on neighborhood quality. Vorst (1987) developed a model of maintenance choice under uncertainty, whereas Anas and Arnott (1991) explicitly included upgrading, downgrading, and demolition choices in their dynamic model. Kutty (1995) expanded the model to consider the inter-temporal nature of the problem, uncertainty, and expectations. However, so far, the above studies were concentrated on the development of theoretical models and no empirical test was carried out. Dubin (1998) tried to simplify the model into two discrete periods and maintenance states. The model was verified by a simulation.

Similarly, in the line of the optimization study of timing of the refurbishment cycle, the positive effects of refurbishment on value were assumed, yet few empirical studies were conducted. Wong and Norman (1994) developed the theory of optimal timing of refurbishment, but justified on a numerical simulation only. Wong (2000) addressed the issue of the lack of empirical tests on their theory, but only a case study was carried out to identify the sensitivities of values to the refurbishment cycle. The assumption of "brand new" conditions achievable by refurbishment is subject to empirical analysis.

Dunse and Jones (1998) have explicitly incorporated interactive terms between age and refurbishment in their hedonic analysis of offices in the Glasgow study. They found that the asking rent of a refurbished office exceeded that of a non-refurbished one in aged-office. However, they adopted a crosssectional hedonic approach which did not distinguish the effects of location from refurbishment. In addition, asking rent is not a good proxy for market value.

\section{Methodology and data}

In this study, a cross-sectional inter-temporal (panel) data analysis is required to separate the value enhancement effects of refurbishment from other factors. This is because panel data, which involves the repeated measurement of the values of individual properties over time, can help measure the price differentials before and after refurbishment. Since refurbishment is applied to the whole building/estate, nonrefurbished buildings/estates are required to act as a control to extricate the price differentials. In the following examples, we will refer to the refurbished estate as Estate A, and the controlled estate as Estate B. The hedonic pricing model is employed to estimate the implicit prices of the property attributes, including the refurbishment. This is achieved by regressing property prices on property characteristics such as building age and floor area. This method allows the heterogeneous property attributes to be standardized so that a like-with-like comparison can be made. Rosen (1974) is the classic reference on the theory of hedonic pricing model.

To operationalize a panel data hedonic pricing model, a large amount of transaction prices and property attributes are needed. In 
Hong Kong, two very large and popular estates meet this stringent data requirement: Pokfulam Garden (PFL - Estate A) and Chi Fu Fa Yuen (CFFY - Estate B). They are actively transacted estates. There were 888 and 3,206 transactions in these estates during the periods July 1991-December 1997 and July 1999-March 2001, respectively. The other reason for choosing this sample selection is that they are located in close proximity to each other, and share common amenities such as bus terminals, shopping arcades, and public services. Furthermore, the two estates have highly similar physical characteristics, such as the range of floor area, number of storeys, and the age of buildings. As a result, much heterogeneity, such as locational differences and marginal price differences of attributes, can be eliminated. Table I shows the summary statistics of the data.

Estate $\mathrm{A}$ has undergone a comprehensive refurbishment at the end of 1998, including a complete replacement of tiles in the external facade and re-plumbing. The preparation works such as the erection of scaffolding commenced in early 1998 and the project was completed in late 1998. The cost of the refurbishment was about $\$ 50$ million in 1997 for a total gross floor area of about 0.91 million square feet. The unit cost of refurbishment is therefore $\$ 55$ per square foot. For example, owners of a 600-squarefoot flat had to pay about $\$ 33,000$ for its refurbishment. In contrast, the adjacent similar Estate B has performed routine maintenance and minor repairs only, thus serving as a control.

\section{The hedonic pricing model}

Specifically, the two estates (Estate A and B) will be estimated by the semi-logarithm hedonic pricing model of equation (1) below by the ordinary least squares (OLS)

technique. The model assumes the effects of refurbishment on property value to be a step function so that significant increases in value only occur beyond a certain threshold:

$$
\begin{aligned}
\ln V & =\alpha_{1}+\alpha_{2} A G E+\alpha_{3} A G E^{2}+\alpha_{4} G F A \\
& +\alpha_{5} G F A^{2}+\alpha_{6} F L O O R+\alpha_{7} F L O O R^{2} \\
& +\alpha_{8} F V I E W \times E A S T+\alpha_{9} F V I E W \\
& \times S O U T H+\alpha_{10} F V I E W \times W E S T \\
& +\alpha_{11} P V I E W \times E A S T+\alpha_{12} P V I E W \\
& \times S O U T H+\alpha_{13} P V I E W \times W E S T \\
& +\alpha_{14} P V I E W \times N O R T H+\alpha_{15} N V I E W \\
& \times E A S T+\alpha_{16} N V I E W \times S O U T H \\
& +\alpha_{17} N V I E W \times W E S T+\beta_{1} E S T \_A \\
& \times P R E_{-} R F M+\beta_{2} E S T \_A \times P O S T \_R F M \\
& +\sum_{t=1}^{T} \chi_{t} T I M E_{t}+\varepsilon
\end{aligned}
$$

where

$V$ is the nominal transaction price of the property in HK dollars;

$A G E$ is the age of the building in months, which equals the difference between the date of issue of the occupation permit and the date of the transaction;

GFA is the gross floor area of the transacted property in square feet;

FLOOR is the floor level of the transacted property;

$F V I E W$ is a dummy variable which equals 1 when the property possesses a panoramic sea view, and zero otherwise;

$P V I E W$ is a dummy variable which equals 1 when the property possesses a partially obstructed sea view, and zero otherwise;

NVIEW is a dummy variable which equals 1 when the property does not possess any sea view, and zero otherwise;

Table I Summary statistics of the transaction data

\begin{tabular}{lccrr}
\hline & Minimum & Maximum & Mean & Standard deviation \\
\hline Pokfulam Garden (PFL - Estate A) & & & & \\
PRICE (HK\$ million) & 0.85 & 9.3 & 3.18 & 1.54 \\
AREA (sf) & 267 & 1345 & 765.13 & 283.31 \\
FLOOR & 1 & 28 & 14.52 & 8.23 \\
AGE (months) & 145 & 252 & 189.73 & 27.88 \\
Chi Fu Fa Yuen (CFFY - Estate B) & & & & \\
PRICE (HKS million) & 0.25 & 7.9 & 2.50 & \\
AREA (sf) & 259 & 1009 & 598.63 & 9.74 \\
FLOOR & 0 & 27 & 13.59 & 7.72 \\
AGE (months) & 127 & 267 & 186.42 & 29.96 \\
\hline
\end{tabular}


EAST, SOUTH, WEST, and NORTH are dummy variables which equal 1 when the property's windows face east, south, west, and north, respectively, and zero otherwise;

$E S T \_A$ is a dummy variable which equals 1 when the property belongs to Estate A Pokfulam Garden, and zero otherwise;

PRE_RFM is a dummy variable which equals 1 when the transaction was engaged before the refurbishment and zero otherwise;

$P O S T_{-}$RFM is dummy variables which equals 1 when the transaction was engaged after the refurbishment and zero otherwise;

$T I M E_{i}$ is a dummy variable which equals 1 when $i$ equals the date of transaction $(t)$, and zero otherwise, where $i$ ranges from July 1991-December 1997 and July 1999-

March 2001;

$\alpha_{k}, \beta_{k}$ and $\chi_{k}$ are the coefficients to be estimated; and

$\varepsilon$ is the stochastic term.

While coefficient $\alpha_{1}$ serves as the intercept, coefficients $\alpha_{2}-\alpha_{17}$ capture the effects of structural and neighborhood attributes.

Square terms are added for the structural attributes ( $A G E, G F A$ and FLOOR) to cater for their non-linear marginal effects. The sign of $A G E$ coefficient is expected to be negative in reflecting the deterioration of the premises with respect to age, but whether such effect is diminishing or increasing is uncertain. The coefficients of GFA and FLOOR are expected to show positive but diminishing effects.

The neighborhood effects come from sea view and orientations. It is expected that a full sea view is preferred to a partially obstructed sea view, which is, in turn, preferred to the absence of any sea view. Orientations are included because a flat facing west is subject to the problem of thermal transmission from the sun. Since orientations also capture the difference in sea views, the dummy variables for orientations and sea views are interacted to orthogonalize them. The FVIEW $\times$

NORTH is missing because the site does not provide any flats facing north, which can enjoy a full sea view. The $N V I E W \times N O R T H$ is dropped as it is the base for other dummy variables. Coefficients $\chi_{i}$ reflect the time effects on the property price.

The focus of this study lies on the coefficients $\beta_{1}$ and $\beta_{2}$, which measure the price differentials between the two estates before and after the refurbishment. Since individual flat attributes are controlled, the difference should reflect the general quality difference between the two estates. Although the refurbishment was completed at the end of 1998 , the expectation of the positive results of the refurbishment may be formed well before the works. Similarly, the outcome of the refurbishment may take time to distribute to the market after the works.

Therefore, a nine-month period before and after the works (January 1998-June 1999) is truncated from the sample data. In other words, the periods to be studied are July 1991December 1997 and July 1999-March 2001.

\section{The repeat-sales approach}

As a cross-check for the results of the hedonic pricing model, a repeat-sales pricing model is utilized to identify the price differentials from the price indexes of the building/estate before and after refurbishment. The advantage of this approach is that the unchanged property attributes can be omitted so that the problem of arbitrarily defined sea views is avoided.

Retaining the assumption that property characteristics and their implicit prices do not change between the first sale $\left(t_{1}\right)$ and the second sale $\left(t_{2}\right)$, Bailey et al. (1963) introduced the following repeat-sales model (BMN model):

$$
\ln \left(\frac{V_{i t_{2}}}{V_{i t_{1}}}\right)=\sum_{t=1}^{T} \alpha_{t} D_{i t}+u_{i t_{1} t_{2}}
$$

where $V_{i t}$ denotes the sales price of house $i$ in period $t(i=1, \ldots, m ; t=0, \ldots, T) ; \alpha_{t}$ denotes the estimated coefficient for time dummy $D_{i t}$; and $u_{i t_{1} t_{2}}$ is the error term. The time dummies are set to take the value -1 if $t=t_{1},+1$ if $t=t_{2}$, and zero otherwise. Note that $\alpha_{0}$ has been set to zero so as to normalize the price index at time period 0 . The model can be thought of the subtraction of two hedonic regression models from the second sale to the first sale. Then the price index can be constructed by the series of $\exp \left(\alpha_{t}\right)$.

\section{Results}

The presentation of the results is divided into two parts. The first part presents the results of the hedonic pricing model. The gross value enhancement effects of the refurbishment will be identified first, and then the net value enhancement effects of the refurbishment will be discussed with reference to the cost of the 
refurbishment. The second part reports the results of the repeat-sales model, which depicts the price differentials in the price indexes of the two estates estimated by the BMN model.

\section{The hedonic pricing model}

The results of the hedonic pricing model are shown in Table II. Most of the coefficients are highly significant. For the structural attributes, the coefficients of $G F A$ and $F L O O R$ and their squared terms are significant at the 1 per cent level with opposite sign, confirming their diminishing marginal effects. Similarly, the coefficients of $A G E$ and its squared term are also significant at the 10 per cent level with expected sign, which reveals the diminishing marginal effects of age. The lower significance of the effects of age is possibly due to the lack of variability of age in the data set in which only two estates were used. For the neighborhood attributes, sea views and orientations appeared to have a significant effect on property values. The negative and significant coefficient of NVIEW $\times W E S T$ indicates that this is the least preferred type of view as far as the two estates are concerned. The results for the time

Table II Regression results on the hedonic pricing model

\begin{tabular}{|c|c|c|}
\hline Independent variables & Coefficient & t-statistics \\
\hline Constant & -0.7641 & $-7.71^{\star \star}$ \\
\hline AGE & -0.0019 & $-1.66^{*}$ \\
\hline$A G E^{2}$ & $5.69 \times 10^{-6}$ & $1.74^{\star}$ \\
\hline GFA & 0.0023 & $35.24^{\star *}$ \\
\hline$G F A^{2}$ & $-5.79 \times 10^{-7}$ & $-15.48^{\star *}$ \\
\hline FLOOR & 0.0100 & $10.54^{\star \star}$ \\
\hline FLOOR ${ }^{2}$ & -0.0002 & $-5.3653^{\star *}$ \\
\hline FVIEW $\times$ EAST & 0.0382 & $5.69^{\star \star}$ \\
\hline FVIEW $\times$ SOUTH & 0.0370 & $5.34^{\star \star}$ \\
\hline FVIEW $\times$ WEST & 0.0276 & $3.23^{\star \star}$ \\
\hline PVIEW $\times$ EAST & 0.0135 & $2.05^{\star}$ \\
\hline PVIEW $\times$ SOUTH & 0.0371 & $6.34^{\star \star}$ \\
\hline PVIEW $\times$ WEST & 0.0517 & $7.01^{\star \star}$ \\
\hline PVIEW $\times$ NORTH & 0.0365 & $3.43^{\star \star}$ \\
\hline NVIEW $\times$ EAST & -0.0010 & -0.20 \\
\hline NVIEW $\times$ SOUTH & 0.0180 & $2.66^{\star \star}$ \\
\hline NVIEW $\times$ WEST & -0.0128 & $-1.90^{\star}$ \\
\hline$E S T \_A \times$ PRE_RFM & -0.0545 & $-12.01^{\star \star}$ \\
\hline$E S T \_A \times$ POST_RFM & 0.0438 & $1.74^{\star}$ \\
\hline Adjusted $R^{2}$ & 0.91 & \\
\hline DW statistic & 2.11 & \\
\hline No. of observations & 4,094 & \\
\hline \multicolumn{3}{|c|}{$\begin{array}{l}\text { Notes: All coefficients are estimated with White's Heteroskedasticity } \\
\text { Consistent standard errors; }{ }^{*} 10 \text { per cent significance; }{ }^{\star \star} 1 \text { per cent } \\
\text { significance }\end{array}$} \\
\hline
\end{tabular}

dummy variables are not shown in the tables for clarity of presentation.

Most importantly, the coefficients of EST_PRE_RFM and EST_POST_RFM estimated the value enhancement effects of refurbishment. It was found that before the refurbishment of Estate $A$, its value was about 5.45 per cent less than that of Estate $B$. However, after the refurbishment, the value of Estate A overtook that of Estate B, with a price difference of about 4.38 per cent. This meant that the value of a flat in Estate A was on average 9.8 per cent higher than that in Estate B (at the price level of July 1991) after the refurbishment. These findings also corresponded to the conclusion drawn from the repeat-sales model.

Making use of the average market value of the estates in July 1991, which was about $\$ 2,391$ per square foot, the value enhanced is therefore $\$ 234$ per square foot. Taking into account the direct cost of refurbishment $\$ 55$ per square foot at the 1997 price level, which is equivalent to $\$ 39$ at the 1991 price level by assuming a 6 per cent discount rate), the net value enhancement provided is about $\$ 195$ per square foot; that is, $\$ 117,000$ for a 600 square-foot flat.

\section{The repeat-sales model}

The price indexes of the two estates, together with the government published property price index of selected popular estates in Hong Kong, are shown in Figure 1. First, the pattern of price change generally follows the government price index. Second, the price indexes show clearly that Estate A underperformed Estate B in market value before the refurbishment (1998), but the market values of the two estates became commensurate after the refurbishment. However, in view of the limited indexing points in the time series, especially after the refurbishment, rigorous tests on the difference cannot be performed.

\section{Conclusions}

This paper proposes a methodology to measure empirically the value enhancement effects of refurbishment in Hong Kong. Two actively transacted estates in close proximity to each other, one of which has undergone the replacement of external tiles, were studied. Panel data was collected and analyzed using a 


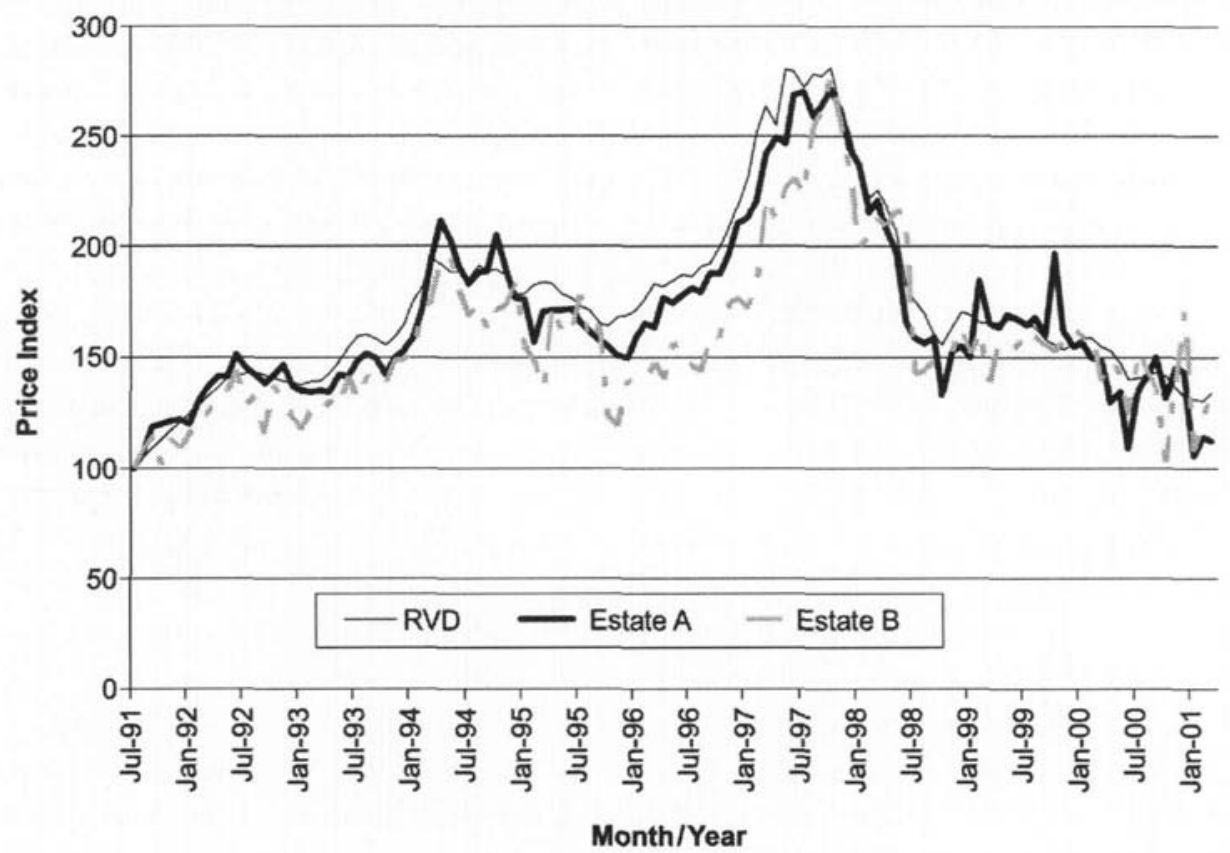

hedonic approach, which was used to estimate the effect of refurbishment on property values. As a control, a repeat-sales model was further estimated to depict the price indexes of the two estates to show the price differentials of the two estates before and after the refurbishment. The data showed that refurbishment increased price levels by approximately 9.8 per cent. The increase in values of the properties far exceeded the cost of refurbishment. This meant that there is a net benefit to refurbishing a housing estate.

Despite the benefit of enhancing property values, refurbishment is obstructed by some other forces in practice. One is the indirect costs associated with disruption, loss of tenant goodwill and loss of amenity during refurbishment. The other is that this benefit can only be captured by a collective decision to refurbish the housing estate. This may not be easily achieved for various reasons. The adjacent housing estate ( $\mathrm{Chi} \mathrm{Fu}$ ), which serves as a control in our analysis, is a good example of the difficulty of reaching a collective decision that is beneficial to all decision makers. In fact, this case is the norm rather than the exception. The externalities generated by the lack of collective decisions to maintain buildings to prevent their premature physical depreciation in Hong Kong are becoming a social problem. What seems to be a win-win situation cannot be easily achieved in practice. While the factors affecting the collective decisions of landlords with regard to refurbishment in a building or housing estate require more in-depth investigation, the results have important practical implications. First, the approach used here demonstrates a method of estimating the value enhancement effects of refurbishment, which can be adopted to evaluate the benefit of refurbishment in other cases. Second, although refurbishment may bring about a net benefit to all property owners in a multipleownership building or housing estate, this may not take place as the property owners may not be able to reach a collective decision. Therefore, efforts should be directed towards means of facilitating this decision-making process. Third, from the property investors' point of view, the governance structure and decision-making process of the owners of a multiple ownership building or housing estate is also an important factor that needs to be taken into account before making investment decisions in these multiple-ownership properties

\section{References}

Arnott, R., Davidson, R. and Pines, D., (1983), "Housing quality, maintenance and rehabilitation", Review of Economic Studies, Vol. 50, pp. 467-94.

Bailey, M.J., Muth, R.F, and Nourse, H.O. (1963), "A regression method for real estate price index 
construction", Journal of the American Statistical Association, Vol. 58, pp. 934-42.

Dildine, L.L. and Massey, F.A. (1974), "Dynamic model of private incentives to housing maintenance", Southern Economic Journal, Vol. 40, pp. 631-39.

Dubin, R.A. (1998)، "Maintenance decisions of absentee landlords under uncertainty", Joumal of Housing Economics, Vol. 7, pp. 144-64.

Elliott, D.S., Quinn, M.A. and Mendelson, R.E. (1985), "Maintenance behavior of large-scale landlords and theories of neighborhood succession", AREUEA Journal, Vol. 13, pp. 424-45.

Kutty, N.K. (1995), "A dynamic model of landlord reinvestment behavior", Journal of Urban Economics, Vol. 37, pp. 212-37.
Ohls, J.C. (1975), "Public policy towards low income housing and filtering in housing markets", Joumal of Urban Economics, Vol. 2, pp. 144-71.

Rosen, S. (1974), "Hedonic prices and implicit markets: product differentiation in pure competition", Joumal of Political Economy, Vol. 82, pp. 34-55.

Sweeney, J.L. (1974), "Quality, commodity hierarchies, and housing market", Econometrica, Vol. 42 No. 1, pp. 147-67.

Vorst, A.C.F. (1987), “Optimal housing maintenance under uncertainty", Journal of Urban Economics, Vol. 21, pp. 209-27.

Wong, K.C. (2000), "Valuing the refurbishment cycle", Property Management, Vol. 18 No. 1, pp. 16-24.

Wong, K.C. and Norman, G. (1994), "The optimal time of renovating a mall", Journal of Real Estate Research, Vol. 9 No. 1, pp. 33-47. 